\title{
Evaluation of Statin Use and Prescribing in Patients with Chronic Kidney Disease Not Receiving Treatment with Kidney Transplant or Dialysis
}

\author{
Hilary Wu, Mazen Sharaf, Karen Shalansky, and Nadia Zalunardo
}

Can J Hosp Pharm. 2021;74(3):219-26

DOI: 10.4212/cjhp.v74i3.3149

\begin{abstract}
Background: Chronic kidney disease (CKD) is a risk factor for cardiovascular disease. The Kidney Disease Improving Global Outcomes 2013 guidelines and the Canadian Cardiovascular Society 2016 guidelines recommend statins for primary prevention of cardiovascular disease in CKD patients aged 50 years or older who are not receiving treatment with kidney transplant or dialysis.
\end{abstract}

Objectives: To evaluate statin use for patients in the Vancouver General Hospital Kidney Care Clinic (VGH KCC) and to gain insight into the KCC nephrologists' practices and perspectives regarding the prescribing of statins for patients with CKD.

Methods: The study comprised 2 parts. Part 1 consisted of a crosssectional study of all statin-eligible patients in the VGH KCC followed by a retrospective chart review. In the chart review, data were collected for 250 statin users and 250 non-users. Logistic regression analyses were performed to determine associations between demographic variables and statin use or non-use. Part 2 was an electronic survey of VGH KCC nephrologists.

Results: Of the 813 statin-eligible patients, 512 (63\%) were taking a statin. Patients were approximately 5 times more likely to be receiving statin therapy when it was indicated for secondary versus primary prevention (adjusted odds ratio 4.64, 95\% confidence interval 2.95-7.47). Eight of the 9 KCC nephrologists completed the survey, and 7 (87.5\%) of these respondents indicated that they never or rarely prescribed statins themselves to KCC patients for primary prevention. However, the same number reported that they sometimes or often suggested statin initiation to family physicians. Three of the respondents indicated agreement with guideline recommendations, but many stated that the decision for statin initiation should be individualized to the patient. Strategies to improve statin prescribing rates that were endorsed by respondents included educating family physicians, creating preprinted orders and laboratory requisitions for statin initiation, providing educational materials about statins to patients, and implementing a protocol for KCC pharmacists to counsel patients about statins.

Conclusions: Many statin-eligible VGH KCC patients were not receiving statin therapy, and most of the KCC nephrologists considered statin prescribing as a role for family physicians. Within the KCC, future directions will be to develop a standardized approach to identify patients who would benefit from statin therapy, and to implement strategies to improve statin prescribing rates in appropriate patients.

Keywords: HMG-CoA reductase inhibitors, statins, chronic kidney insufficiency, cardiovascular disease, primary prevention

\begin{abstract}
RÉSUMÉ
Contexte : L'insuffisance rénale chronique (IRC) est un facteur de risque de maladie cardiovasculaire. Les directives du Kidney Disease Improving Global Outcomes de 2013 et celles de la Société canadienne de cardiologie de 2016 recommandent l'utilisation de statines comme mode de prévention principal des maladies cardiovasculaires par les patients âgés d'au moins 50 ans et souffrant d'IRC, qui ne reçoivent pas de traitement par greffe rénale ou dialyse.

Objectifs : Évaluer l'utilisation des statines pour les patients résidant au Vancouver General Hospital Kidney Care Clinic (VGH KCC) et améliorer la compréhension des pratiques et points de vue des néphrologues de la KCC concernant la prescription de statines aux patients souffrant d'une IRC.

Méthodes : L'étude comportait deux parties. La première consistait en une étude transversale de tous les patients admis à recevoir des statines au VGH $K C C$, suivie d'un examen rétrospectif des dossiers. Les données destinées à cet examen ont été recueillies auprès de 250 utilisateurs de statines et de 250 non-utilisateurs. Les analyses de régression logistique ont permis de déterminer les associations entre les variables démographiques et l'utilisation (ou non) de statines. La deuxième partie consistait en une enquête menée électroniquement auprès des néphrologues du VGH KCC.
\end{abstract}

Résultats : Des 813 patients admissibles à l'utilisation de statines, 512 (63\%) en prenaient déjà. Les patients avaient environ cinq fois plus de chances de recevoir un traitement par statines, lorsque celles-ci étaient indiquées pour la prévention secondaire ou primaire (rapport de cote révisé 4,64, 95 \% intervalle de confiance 2,95 - 7,47). Huit des neuf néphrologues de la KCC ont participé à l'enquête et sept $(87,5 \%)$ d'entre eux ont indiqué qu'ils n'avaient jamais, ou rarement, prescrit de statines aux patients du KCC dans le cadre d'une intervention primaire. Cependant, le même nombre de répondants a indiqué avoir parfois ou souvent proposé aux médecins de famille de commencer un traitement aux statines. Trois répondants ont indiqué être d'accord avec les recommandations préconisées dans les directives, mais bon nombre des néphrologues interrogés ont signalé que la décision d'entreprendre un tel traitement devait être individualisée. Les stratégies visant à améliorer les taux de prescription de statines approuvées par les répondants comprenaient la sensibilisation des médecins de famille, la création d'ordonnances et de demandes d'analyse en laboratoire préimprimées pour entreprendre un traitement aux statines, l'offre aux patients de matériel de formation sur le sujet et la mise en place d'un protocole pour les pharmaciens de la KCC leur permettant de conseiller les patients.

Conclusions : Beaucoup de patients admissibles à un traitement aux statines du VGH KCC ne le recevaient pas, et la plupart des néphrologues de la KCC considéraient que la prescription de ce type de traitement relevait des médecins de famille. Au sein de la KCC, les orientations futures consisteront à élaborer une approche standardisée pour identifier les patients qui tireraient profit d'une thérapie aux statines et à mettre en place des stratégies visant à améliorer les taux de prescription de statines aux patients concernés.

Mots-clés : inhibiteurs de l'HMG-CoA réductase, statines, insuffisance rénale chronique, maladie cardiovasculaire, prévention primaire 


\section{INTRODUCTION}

Chronic kidney disease (CKD) is defined as abnormalities of kidney structure or laboratory markers of kidney damage that are present for at least 3 months. ${ }^{1}$ Laboratory criteria meeting the definition of CKD include a urine albuminto-creatinine ratio greater than $3.0 \mathrm{mg} / \mathrm{mmol}$ or an estimated glomerular filtration rate (eGFR) less than $60 \mathrm{~mL} / \mathrm{min} / 1.73 \mathrm{~m}^{2}$ for at least 3 months. ${ }^{1}$ CKD has been shown to be an independent risk factor for cardiovascular disease. ${ }^{2}$

In the population of patients with CKD who are not receiving renal replacement therapy with kidney transplant or dialysis, statins (HMG-CoA reductase inhibitors) have demonstrated benefit in reducing atherosclerotic events. ${ }^{3}$ To date, the SHARP trial is the largest study to investigate the benefits of statin use specifically in patients with CKD. ${ }^{4}$ This study, published in 2011, was a randomized doubleblind trial that compared the combination of simvastatin $20 \mathrm{mg}$ and ezetimibe $10 \mathrm{mg}$ with placebo in 9270 patients with CKD and no history of myocardial infarction or coronary revascularization. Sixty-seven percent of the patients were not receiving dialysis, and the average age was 62 years in both groups. The combination of simvastatin and ezetimibe was associated with a statistically significant reduction in major atherosclerotic events relative to placebo ( $11.3 \%$ versus $13.4 \%$; rate ratio $0.83,95 \%$ confidence interval [CI] $0.74-0.94)$. These results were driven primarily by a reduction in ischemic strokes and arterial revascularization procedures. Among the 6247 patients who were not receiving dialysis at randomization, the combination of simvastatin and ezetimibe was not associated with any significant reduction in CKD progression.

On the basis of available evidence, the Kidney Disease Improving Global Outcomes (KDIGO) 2013 guidelines recommend initiation of statin therapy for primary prevention of cardiovascular disease in CKD patients who are 50 years of age or older and are not receiving treatment with kidney transplant or dialysis (grade $1 \mathrm{~A}$ recommendation). ${ }^{1}$ The Canadian Cardiovascular Society (CCS) 2016 guidelines also recognize CKD as a significant risk factor for cardiovascular disease, and CKD is listed as a statin-indicated condition in individuals 50 years and older. ${ }^{5}$

The Vancouver General Hospital Kidney Care Clinic (VGH KCC) enrolls CKD patients who are not receiving dialysis and have not undergone kidney transplant. Most of these patients are at least 50 years old and thus would be "statin-eligible" according to guideline recommendations. However, it has been observed that many KCC patients are currently not receiving statin therapy for primary prevention. In addition, the KCC nephrologists infrequently prescribe statins themselves, although they may suggest that a patient's family physician initiate a statin.

The primary objective of this study was to determine the proportion of statin-eligible patients enrolled in the
VGH KCC who were receiving statin therapy. The secondary objectives were to gain insight into KCC nephrologists' practices and perspectives with regard to prescribing statins for CKD patients, to determine associations between demographic variables and statin use or non-use, and to estimate the odds of statin use when indicated for secondary versus primary prevention of cardiovascular disease.

\section{METHODS}

\section{Study Setting}

The VGH KCC provides care for approximately 1300 patients with CKD who have not received a kidney transplant and are not receiving dialysis. Patients are referred to the clinic after first being assessed by a VGH nephrologist. Nephrologists refer patients to the KCC if it is thought that they would benefit from a multidisciplinary approach to their renal care or if their renal function has declined to the point that they require education about kidney replacement therapy. Although some patients may be referred to the clinic immediately after the nephrologist's first assessment, a patient may be followed by their nephrologist for years before referral. The KCC health care team comprises pharmacists, nurses, dietitians, social workers, and nephrologists.

During the first KCC visit, each patient is seen by all members of the care team, with the exception of the nephrologist. At all subsequent visits, the patient is seen by their nephrologist and a clinic nurse; in addition, depending on their needs, the patient may also be seen by a pharmacist, dietitian, and/or social worker. The frequency of clinic visits is determined by the nephrologist according to the patient's clinical status and required level of care. The frequency generally ranges between monthly and yearly.

At each clinic visit, the patient's medications are reviewed by a pharmacist, nurse, or nephrologist, and the clinic nurse or pharmacist updates the patient's medication list in an electronic provincial database (PROMIS). The nephrologist completes a dictated note indicating the patient's past medical history and recent progress, as well as any medication recommendations to be considered by the patient's family physician. The dictation is subsequently uploaded to PROMIS and forwarded to the family physician.

\section{Study Design and Population}

This study comprised 2 parts that were conducted concurrently. It was approved by the University of British Columbia Clinical Research Ethics Board and by the Vancouver Coastal Health Research Institute. The need for informed consent was waived for part 1 , and participants provided written consent in part 2.

Part 1 consisted of a single-centre cross-sectional study, followed by a retrospective chart review. VGH KCC patients were identified from PROMIS for study inclusion 
if they were statin-eligible, based on the KDIGO 2013 and CCS 2016 guideline recommendations for patients with CKD. Thus, study inclusion criteria were enrolment in the VGH KCC; age 50 years or older; and a most recent eGFR less than $60 \mathrm{~mL} / \mathrm{min} / 1.73 \mathrm{~m}^{2}$ and/or most recent albumin-to-creatinine ratio greater than $3.0 \mathrm{mg} / \mathrm{mmol}$. Patients were excluded if they had a documented allergy to statin therapy or had attended fewer than 2 KCC appointments.

In the cross-sectional study component of part 1, data were collected from PROMIS on October 24, 2018, to determine the proportion of statin-eligible patients who were receiving statin therapy at the time. For the secondary analysis, all statin-eligible patients were separated into 2 groups according to whether they were statin users or non-users. A random number generator was then used to assign a number to each individual patient. Chart reviews were conducted for the patients who were assigned numbers 1 to 250 in each list. The total sample size of 500 patients for this analysis was determined with consideration of the time and resources available for data collection. Each chart review involved an assessment of the patient's most recent nephrologist dictation and demographic data available in PROMIS on or before October 24, 2018. Patients were then classified as having an indication for primary or secondary prevention of cardiovascular disease on the basis of documented comorbidities. Patients were considered to have an indication for secondary prevention if they had documented coronary artery disease, ischemic cerebrovascular disease, peripheral artery disease, and/or abdominal aortic aneurysm. The remaining patients were considered to have an indication for only primary prevention of cardiovascular disease.

In part 2 of the study, an electronic survey was developed to assess the perspectives on statin prescribing of the $9 \mathrm{VGH}$ KCC nephrologists (Appendix 1, available at https://www .cjhp-online.ca/index.php/cjhp/issue/view/205). The survey was created using Qualtrics software, and the link to the survey was sent by email to the nephrologists on November 14, 2018. The survey remained open for 1 month. The responses were anonymous and were reviewed by the investigators after the survey had been closed.

\section{Statistical Analysis}

The proportion of statin-eligible patients who were receiving a statin was calculated as a percentage in part 1 of the study. The demographic characteristics of the 250 statin users and 250 non-users randomly selected for chart review were compared using the Student $t$ test for quantitative variables and the $\chi^{2}$ test for categorical variables.

Univariate logistic regression analyses were performed to determine unadjusted associations between demographic variables and statin use or non-use. Variables with associations having $p$ values less than 0.1 were included in a multivariate logistic regression model to adjust for potential confounders. The $p$ value threshold of 0.1 (instead of 0.05 ) was selected to increase sensitivity for detecting potentially relevant variables. Sex and ischemic cerebrovascular disease were also included in the model, as the study team deemed these to be clinically important variables. Adjusted odds ratios (ORs) and 95\% confidence intervals (CIs) were estimated. A second multivariate logistic regression analysis was performed specifically to compare the estimated odds of statin use when indicated for secondary versus primary prevention of cardiovascular disease.

All statistical tests were 2-tailed, and $p$ values less than 0.05 were considered to be significant in the multivariate logistic regression models. Excel 2010 (Microsoft Corporation) and R 3.3.1 software were used for all statistical analyses.

In part 2 of the study, nephrologists' survey responses to multiple-choice questions were compiled and analyzed using descriptive statistics in Excel 2010 (Microsoft Corporation).

\section{RESULTS}

\section{Cross-Sectional Study}

Of the 982 patients who met the inclusion criteria, 169 patients were excluded, most because they had attended fewer than 2 KCC appointments (Figure 1). Of the 813 statin-eligible patients who met the study criteria, 512 (63\%) were documented as receiving statin therapy.

\section{Patient Characteristics in Retrospective Chart Review}

The demographic characteristics of the 500 patients randomly selected for chart review are summarized in Table 1. The mean age was 76 years, and 291 (58\%) were male. Most of the patients had both reduced eGFR (overall mean $25.5 \mathrm{~mL} / \mathrm{min} / 1.73 \mathrm{~m}^{2}$ ) and elevated albumin-to-creatinine ratio (overall mean $97.7 \mathrm{mg} / \mathrm{mmol}$ ). In addition to CKD, all of the patients had at least one other cardiovascular risk

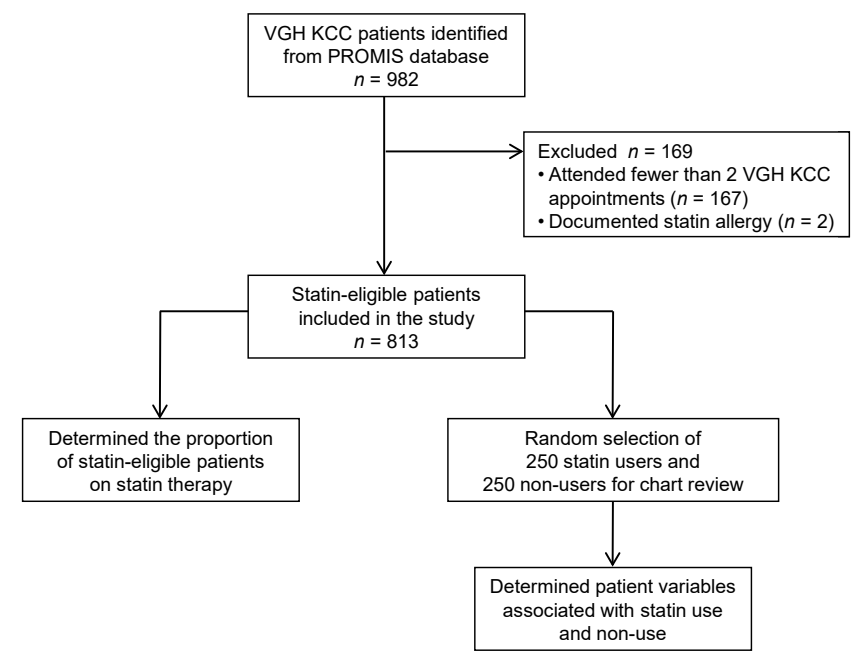

FIGURE 1. Study flow diagram for part 1 of the study. VGH KCC = Vancouver General Hospital Kidney Care Clinic. 
Study Group; No. (\%) of Patients ${ }^{\mathrm{a}}$

\begin{tabular}{|c|c|c|c|c|c|}
\hline \multirow[b]{2}{*}{ Characteristic } & \multirow{2}{*}{\multicolumn{2}{|c|}{$\begin{array}{l}\text { Statin Users } \\
\quad(n=250)\end{array}$}} & \multirow{2}{*}{\multicolumn{2}{|c|}{$\begin{array}{l}\text { Statin Non-users } \\
\quad(n=250)\end{array}$}} & \multirow[b]{2}{*}{$p$ Value } \\
\hline & & & & & \\
\hline Age (years) (mean $\pm S D)$ & \multicolumn{2}{|c|}{$77 \pm 8$} & \multicolumn{2}{|c|}{$75 \pm 10$} & 0.048 \\
\hline Sex, male & 155 & $(62)$ & 136 & $(54)$ & 0.10 \\
\hline eGFR $\left(\mathrm{mL} / \mathrm{min} / 1.73 \mathrm{~m}^{2}\right)($ mean $\pm \mathrm{SD})$ & \multicolumn{2}{|c|}{$26 \pm 10$} & \multicolumn{2}{|c|}{$25 \pm 10$} & 0.18 \\
\hline ACR $(\mathrm{mg} / \mathrm{mmol})($ mean $\pm \mathrm{SD})$ & \multicolumn{2}{|c|}{$100.0 \pm 133.0$} & \multicolumn{2}{|c|}{$95.2 \pm 125.0$} & 0.71 \\
\hline Laboratory criteria for CKD & & & & & 0.17 \\
\hline Reduced eGFR only & 45 & $(18)$ & 58 & $(23)$ & \\
\hline Albuminuria only & 4 & $(2)$ & 1 & $(<1)$ & \\
\hline Reduced eGFR and albuminuria & 201 & $(80)$ & 191 & (76) & \\
\hline Body mass index $\left(\mathrm{kg} / \mathrm{m}^{2}\right)($ mean $\pm \mathrm{SD})$ & \multicolumn{2}{|c|}{$28.1 \pm 6.2$} & \multicolumn{2}{|c|}{$26.5 \pm 5.3$} & 0.002 \\
\hline Ethnicity & & & & & 0.004 \\
\hline White & 109 & $(44)$ & 146 & (58) & \\
\hline Asian & 117 & $(47)$ & 85 & (34) & \\
\hline Other & 24 & $(10)$ & 19 & (8) & \\
\hline Current smoker & 7 & (3) & 10 & (4) & 0.62 \\
\hline \multicolumn{6}{|l|}{ Comorbidities } \\
\hline Hypertension & 233 & (93) & 213 & $(85)$ & 0.006 \\
\hline Diabetes mellitus & 159 & (64) & 71 & $(28)$ & $<0.001$ \\
\hline Dyslipidemia & 136 & $(54)$ & 50 & $(20)$ & $<0.001$ \\
\hline Coronary artery disease & 87 & (35) & 16 & (6) & $<0.001$ \\
\hline Ischemic cerebrovascular disease & 33 & $(13)$ & 22 & (9) & 0.15 \\
\hline Peripheral artery disease & 12 & (5) & 8 & (3) & 0.49 \\
\hline Abdominal aortic aneurysm & 7 & (3) & 3 & (1) & 0.34 \\
\hline Indication for statin & & & & & $<0.001$ \\
\hline Primary prevention of cardiovascular disease & 138 & $(55)$ & 208 & $(83)$ & \\
\hline Secondary prevention of cardiovascular disease $\mathrm{e}^{\mathrm{b}}$ & 112 & $(45)$ & 42 & $(17)$ & \\
\hline Kidney replacement therapy plan & & & & & 0.25 \\
\hline Conservative care & 27 & $(11)$ & 42 & $(17)$ & \\
\hline Hemodialysis & 25 & $(10)$ & 27 & $(11)$ & \\
\hline Peritoneal dialysis & 20 & (8) & 18 & (7) & \\
\hline Undecided & 178 & (71) & 163 & $(65)$ & \\
\hline
\end{tabular}

$\mathrm{ACR}=$ albumin-to-creatinine ratio, $\mathrm{CKD}=$ chronic kidney disease, eGFR = estimated glomerular filtration rate, $\mathrm{SD}=$ standard deviation.

aExcept where indicated otherwise.

'b Indications for secondary prevention of cardiovascular disease were coronary artery disease, ischemic cerebrovascular disease, peripheral artery disease, and/or abdominal aortic aneurysm.

factor (i.e., hypertension, diabetes mellitus, dyslipidemia, and/or clinical atherosclerosis). The statin users were significantly older and had higher body mass index than the non-users. Ethnicity differed between the 2 groups as well: most statin users were of Asian background, whereas the majority of statin non-users were white. In addition, compared with statin non-users, higher proportions of statin users had documented diagnoses of hypertension, diabetes mellitus, dyslipidemia, and coronary artery disease. When comorbidities were categorized as indications for primary or secondary prevention of cardiovascular disease, a significantly greater proportion of statin users had at least 1 indication for secondary prevention, relative to non-users $(45 \%$ versus $17 \%, p<0.001)$.

\section{Multivariate Logistic Regression Models for Statin Use and Non-use}

In the first multivariate logistic regression model, which was used to determine associations between demographic variables and statin use or non-use, several factors were positively associated with statin use after adjustment for potential confounders (Table 2). These included older age, Asian ethnicity 
TABLE 2. Multivariate Logistic Regression Model for Association between Patient Variables and Statin Use $(n=500)$

\begin{tabular}{|c|c|c|c|}
\hline Variable & Adjuste & d OR $(95 \% \mathrm{Cl})$ & $p$ Value \\
\hline Age, per 1-year increase & 1.03 & $(1.00-1.06)$ & $<0.05$ \\
\hline Male sex, relative to female sex & 1.00 & $(0.64-1.56)$ & NSS \\
\hline Kidney replacement therapy plan & & & \\
\hline Conservative care & 1.00 & (reference) & - \\
\hline Hemodialysis & 2.75 & $(1.04-7.38)$ & $<0.05$ \\
\hline Peritoneal dialysis & 6.14 & $(2.12-18.35)$ & $<0.01$ \\
\hline Undecided & 3.61 & $(1.69-7.93)$ & $<0.01$ \\
\hline $\begin{array}{l}\text { Body mass index, per 1-unit } \\
\text { increase }\end{array}$ & 1.03 & $(0.99-1.08)$ & NSS \\
\hline Ethnicity & & & \\
\hline White & 1.00 & (reference) & - \\
\hline Asian & 1.68 & $(1.03-2.75)$ & $<0.05$ \\
\hline Other & 1.48 & $(0.67-3.31)$ & NSS \\
\hline $\begin{array}{l}\text { Comorbidity, relative to } \\
\text { absence of the comorbidity }\end{array}$ & & & \\
\hline Hypertension & 1.10 & $(0.53-2.35)$ & NSS \\
\hline Diabetes mellitus & 2.75 & $(1.75-4.34)$ & $<0.01$ \\
\hline Dyslipidemia & 3.89 & $(2.47-6.20)$ & $<0.01$ \\
\hline Coronary artery disease & 8.60 & $(4.58-17.11)$ & $<0.01$ \\
\hline $\begin{array}{l}\text { Ischemic cerebrovascular } \\
\text { disease }\end{array}$ & 1.85 & $(0.88-3.94)$ & NSS \\
\hline
\end{tabular}

$\mathrm{Cl}=$ confidence interval, NSS $=$ not statistically significant, $\mathrm{OR}=$ odds ratio.

(relative to white ethnicity), and diagnoses of dyslipidemia, diabetes mellitus, or coronary artery disease. Patients with a plan for conservative care (i.e., no kidney replacement therapy in the event of end-stage renal disease) were less likely to be taking a statin than were patients with plans for dialysis. The patient factor having the largest association with statin use was coronary artery disease, with an adjusted OR of 8.60 (95\% CI 4.58-17.11). However, no statistically significant association was found between statin use and ischemic cerebrovascular disease.

In the second multivariate logistic regression model, the estimated odds of statin use were compared when indicated for secondary versus primary prevention of cardiovascular disease. Patients were approximately 5 times more likely to be receiving statin therapy when it was indicated for secondary prevention, with an OR of 4.64 (95\% CI $2.95-$ 7.47) after adjustment for age, sex, ethnicity, body mass index, and kidney replacement therapy plan.

\section{Survey of Nephrologists}

Of the 9 KCC nephrologists, 8 completed the survey during the allotted time. The number of years of nephrology experience varied across respondents; one nephrologist had less than 5 years, 2 had 5-15 years, 4 had 16-25 years, and one had more than 25 years of experience.
For the purpose of this survey, "prescribing" referred to initiating therapy, as opposed to providing a prescription to continue existing therapy. The majority (6 [75\%]) of the respondents believed it was appropriate for statins to be initiated by any of a CKD patient's regular physicians, including the patient's nephrologist. Nevertheless, all but 1 respondent (7 [87.5\%]) stated that they never or rarely prescribed statins themselves for primary prevention of cardiovascular disease in KCC patients. Most (5 [62.5\%]) also reported never or rarely prescribing statins for secondary prevention themselves. The remaining respondents indicated that they prescribed statins sometimes (1 [12.5\%] and 3 [37.5\%] for primary and secondary prevention, respectively). The frequency of suggesting statins was higher; in fact, 7 respondents $(87.5 \%)$ indicated that they sometimes or often suggested statin initiation to the family physicians of KCC patients for both primary and secondary prevention. The nephrologists were asked to select potential obstacles to prescribing or suggesting statin therapy during KCC appointments, and time constraints were acknowledged by 4 respondents (50\%).

Respondents identified various reasons for electing not to prescribe statins for primary prevention of cardiovascular disease: statin initiation not being a priority, need for monitoring, and drug interactions were each selected by 4 respondents (50\%), and risk of adverse effects and increased pill burden were each selected by 5 respondents (62.5\%). Only 2 respondents (25\%) indicated that prescribing statins was outside their scope of practice.

Three $(37.5 \%)$ of the respondents stated that "lack of evidence of benefit" was a potential reason for not initiating statin therapy for primary prevention. When the nephrologists were asked about their agreement with the KDIGO 2013 and CCS 2016 guideline recommendations, only 3 respondents $(37.5 \%)$ indicated agreement. The remaining respondents stated that they disagreed $(3[37.5 \%])$ or were undecided $(2[25 \%])$, and these individuals were asked to provide their rationales. The most common responses were that the decision for statin initiation should be patientspecific, that the benefits of statin initiation may not be consistent across the entire spectrum of renal disorders, and that patients with limited life expectancy likely would not derive much benefit from statins.

Table 3 outlines respondents' perceptions about proposed strategies to increase statin prescribing rates for primary prevention of cardiovascular disease in KCC patients. Creating preprinted statin dosing orders, creating preprinted laboratory requisitions, providing educational materials about statins to patients, and implementing a protocol for KCC pharmacists to counsel patients about statins were each endorsed by 3 (37.5\%) of the respondents. Providing education to family physicians about statins in CKD was the most preferred strategy: 5 respondents (62.5\%) endorsed this approach. 
TABLE 3. Nephrologists' Opinions on Proposed Strategies to Increase Statin Prescribing Rates for Primary Prevention of Cardiovascular Disease in Vancouver General Hospital KCC Patients

No. of Nephrologists Believing Strategy Would Be Beneficial

Proposed Strategy $(n=8)$

\begin{tabular}{ll}
\hline $\begin{array}{l}\text { Education for family physicians about } \\
\text { statins in CKD }\end{array}$ & 5 \\
\hline $\begin{array}{l}\text { Preprinted order with statin options and } \\
\text { dosing recommendations }\end{array}$ & 3 \\
\hline $\begin{array}{l}\text { Preprinted laboratory requisition for } \\
\text { patients initiating statins }\end{array}$ & 3 \\
\hline $\begin{array}{l}\text { Protocol for KCC pharmacist to counsel } \\
\text { patients initiating statins }\end{array}$ & 3 \\
\hline $\begin{array}{l}\text { Educational materials about statins for KCC } \\
\text { patients }\end{array}$ & 3 \\
\hline $\begin{array}{l}\text { Increased duration of KCC appointments } \\
\text { Reminder on KCC patient assessment sheets }\end{array}$ & 1 \\
\hline $\begin{array}{l}\text { Education for nephrologists about statins } \\
\text { in CKD }\end{array}$ & 1 \\
\hline $\begin{array}{l}\text { Education for KCC allied health staff about } \\
\text { statins in CKD }\end{array}$ & 1 \\
\hline
\end{tabular}

$\mathrm{CKD}=$ chronic kidney disease, $\mathrm{KCC}=$ Kidney Care Clinic.

\section{DISCUSSION}

To our knowledge, this is the first study evaluating statin use in a multidisciplinary CKD clinic. We found that 512 (63\%) of 813 statin-eligible patients in the KCC were receiving a statin. This rate of statin use is of concern because CKD is an established risk factor for cardiovascular disease, and most studies suggest that patients with CKD are 20 times more likely to die of cardiovascular disease than to develop end-stage renal disease. ${ }^{6}$ Therefore, efforts should be made to reduce cardiovascular risk as much as possible. Although the KDIGO 2013 and CCS 2016 guidelines would both recommend statin therapy for every patient in this study, close to $40 \%$ of them were not receiving a statin. The results of the multivariate analyses revealed that the patients were much more likely to be taking a statin if they had an indication for secondary prevention of cardiovascular disease, especially coronary artery disease. This may reflect the well-established evidence for statins in patients with coronary artery disease, ${ }^{7}$ as well as the fact that statins are included on preprinted orders for patients who are admitted for acute coronary syndromes in our province.

Our survey of nephrologists provided insights into possible reasons why statins are not more widely prescribed for primary prevention of cardiovascular disease in our
KCC. Several nephrologists did not fully agree with the KDIGO 2013 and CCS 2016 recommendations because they believed that a patient-individualized approach was necessary to make decisions about statin initiation. Many of their concerns stemmed from potentially unfavourable risk-benefit ratios of statin use in certain populations, particularly elderly patients with limited life expectancy. This is perhaps the explanation for the lower odds of statin use among patients with plans for conservative care, as compared with patients for whom plans for dialysis were in place. Patients who have elected conservative care are typically older and frailer, and therefore less likely to derive long-term benefit from statin therapy. As a group, these KCC nephrologists appeared to initiate statins themselves more frequently for secondary prevention; 37.5\% reported prescribing statins "sometimes" for secondary prevention, as compared to only $12.5 \%$ for primary prevention. This result is likely due to the perception that statin initiation is more important and has a more favourable risk-benefit ratio in the setting of clinical atherosclerosis.

The survey results also revealed potential areas for future study. A few nephrologists expressed uncertainty about the benefits of statin therapy across the spectrum of renal disorders. Although the SHARP trial ${ }^{4}$ investigated the benefits of statin use for patients with $\mathrm{CKD}$, the particular causes of CKD were not specified in that study, and it is therefore unclear whether its results are truly generalizable to all CKD patients. Future studies are warranted to elucidate this matter.

With respect to the VGH KCC nephrologists' prescribing practices, most of the survey respondents did not indicate that initiating statins was outside their scope of practice. In fact, a few respondents endorsed the creation of preprinted statin dosing orders and laboratory requisitions, which would serve to improve prescribing efficiency during KCC appointments. However, it appears that the respondents generally recommended statin initiation to family physicians more frequently than they prescribed statins themselves. In addition, providing education to family physicians was their most popular strategy to increase statin prescribing rates for primary prevention in KCC patients. These last 2 findings suggest that most of the nephrologists would prefer that family physicians be responsible for initiating statins. One reason for this preference may be the need for close monitoring when statin therapy is started, which was indicated as a barrier to prescribing statins by $50 \%$ of the respondents. Nephrologists may perceive family physicians as being better suited to initiate statins because they have more frequent follow-up with patients, which allows for closer monitoring for adverse events. Furthermore, among our KCC patients, it has been observed that family physicians often initiate statins and provide monitoring when recommended to do so by other specialists (e.g., cardiologists and neurologists). 
The nephrologists' preference to defer statin initiation to alternate prescribers could also be an indication that they consider this intervention to be of low priority in their practices. Indeed, when the nephrologists were asked about prescribing statins for primary prevention, $50 \%$ expressed that it was not a priority. This response may be due to the lack of benefit seen with statin use, in terms of slowing CKD progression. Nephrologists likely place greater priority on renal-specific issues, such as interventions that delay CKD progression (e.g., hypertension and diabetes management, use of renin-angiotensin-aldosterone system inhibitors), management of anemia and mineral bone disorders, and plans for kidney replacement therapy.

The KCC nephrologists generally considered statin prescribing to be a role for family physicians, but nephrologists' practices may differ according to the particular CKD population and clinical setting. To date, this is the first study to evaluate nephrologists' opinions about statin therapy in CKD patients who are not receiving treatment with kidney transplant or dialysis. One previous multicentre study surveyed nephrologists about their attitudes toward statin use specifically in the population of patients receiving hemodialysis. ${ }^{8}$ All of the 72 respondents indicated that they prescribed statins for hemodialysis patients, and $83 \%$ stated that they prescribed statins for secondary prevention of cardiovascular disease; prescribing practices for primary prevention were not described. These results may reflect the nephrologists' choice to continue statin therapy, given that the study definition of "prescribing" was not limited to therapy initiation. However, all of the respondents were able to list the parameters that they routinely monitored before and during statin initiation. Overall, compared with the nephrologists in our KCC, the nephrologists in this earlier study appeared to assume more responsibility for their patients' statin treatment. Possible reasons for this finding may be nephrologists' higher frequency of contact with patients in the hemodialysis versus KCC setting, as well as nephrologists' awareness that other physicians are often reluctant to prescribe medications to hemodialysis patients because of concerns about adverse effects and contraindications.

The rate of statin use in our clinic was found to be suboptimal; however, this presents an opportunity for the KCC pharmacists to play an important role in improving cardiovascular risk management for our patients. The KCC pharmacists are well positioned to help patients make informed decisions about statin initiation, to provide statin recommendations for appropriate patients, and to facilitate the communication of recommendations between nephrologists and family physicians.

This study had a number of limitations. First, it was conducted only in the VGH KCC, and the data on statin use and nephrologists' perspectives that we found may differ from those of other renal centres. In addition, patient classification of statin use or non-use was dependent on KCC pharmacists and nurses having updated medication lists in the PROMIS database. It is possible that some statin initiations and discontinuations were not entered in the system. Furthermore, given the cross-sectional design of part 1, it was not possible to determine the indication or indications for which the statins were originally prescribed (for those patients who were receiving statin therapy). Therefore, it could not be determined whether patients were originally initiated on statins for the purpose of primary or secondary prevention of cardiovascular disease. Another limitation was that the chart reviews conducted for the multivariate analyses were limited to nephrologist dictations, which may have contained inaccurate or incomplete data about patient comorbidities. Lastly, a sample size calculation was not done before conducting the chart reviews; instead, the sample size of 500 patients (250 statin users and 250 nonusers) was selected according to the availability of time and resources. Nevertheless, several statistically significant associations were found between patient variables and statin use or non-use.

\section{CONCLUSION}

The majority of statin-eligible CKD patients in our KCC were receiving statin therapy. However, $37 \%$ of the patients were not receiving statin therapy despite having relevant indications, and these patients were therefore not receiving guideline-recommended care. Patients were much more likely to be receiving statin therapy if they had an indication for secondary prevention of cardiovascular disease, signalling that statin initiation for primary prevention may require greater emphasis in our clinic. Within the VGH KCC, future directions will be to further explore nephrologists' opinions about the guidelines for statin use and to develop a standardized approach to identify CKD patients for whom the benefits of statin therapy would outweigh the risks, based on individual patient factors. Nephrologist-preferred strategies will then be implemented to increase statin prescribing rates in appropriate patients, with a focus on providing education to family physicians. Ultimately, this may help to improve cardiovascular outcomes in our CKD patients.

\section{References}

1. Kidney Disease: Improving Global Outcomes (KDIGO) Lipid Work Group. KDIGO clinical practice guideline for lipid management in chronic kidney disease. Kidney Int Suppl. 2013;3(3):259-305.

2. Ardhanari S, Alpert MA, Aggarwal K. Cardiovascular disease in chronic kidney disease: risk factors, pathogenesis, and prevention. Adv Perit Dial. 2014;30(2):40-53.

3. Chronic Kidney Disease Prognosis Consortium; Matsushita K, van der Velde M, Astor BC, Woodward M, Levey AS, de Jong PE, et al. Association of estimated glomerular filtration rate and albuminuria with all-cause and cardiovascular mortality in general population cohorts: a collaborative meta-analysis. Lancet. 2010; 375(9731):2073-81.

4. Baigent C, Landray MJ, Reith C, Emberson J, Wheeler DC, Tomson $\mathrm{C}$, et al. The effects of lowering LDL cholesterol with simvastatin plus ezetimibe in patients with chronic kidney disease (Study of 
Heart and Renal Protection): a randomised placebo-controlled trial. Lancet. 2011;377(9784):2181-92.

5. Anderson TJ, Grégoire J, Pearson GJ, Barry AR, Couture P, Dawes M, et al. 2016 Canadian Cardiovascular Society guidelines for the management of dyslipidemia for the prevention of cardiovascular disease in the adult. Can J Cardiol. 2016;32(11):1263-82.

6. Foley RN, Parfrey PS, Sarnak MJ. Clinical epidemiology of cardiovascular disease in chronic renal disease. Am J Kidney Dis. 1998;32(5 Suppl 3):S112-9.

7. Vrecer M, Turk S, Drinovec J, Mrhar A. Use of statins in primary and secondary prevention of coronary heart disease and ischemic stroke. Meta-analysis of randomized trials. Int J Clin Pharmacol Ther 2003;41(12):567-77.

8. Budzisz E, Nowicki M. Opinions of nephrologists on the efficacy and tolerance of statins in hemodialysis patients. Ren Fail. 2017; 39(1):277-82.
Hilary Wu, BSc(Pharm), ACPR, PharmD, is with Vancouver General Hospital, Vancouver, British Columbia.

Mazen Sharaf, BSc(Pharm), ACPR, is with UBC Hospital, Vancouver Coastal Health, Vancouver, British Columbia.

Karen Shalansky, PharmD, FCSHP, is with Vancouver General Hospital, Vancouver, British Columbia.

Nadia Zalunardo, MD, SM, FRCPC, is with Vancouver General Hospital Vancouver, British Columbia.

Competing interests: None declared.

\section{Address correspondence to:}

Dr Hilary Wu

Vancouver General Hospital - Gordon and Leslie Diamond Health Care Centre 2775 Laurel Street Vancouver BC V5Z $1 \mathrm{M} 9$

email: hilary.wu2@vch.ca

Funding: Funding for statistical support was provided by the Vancouver General Hospital Renal Program.

Acknowledgement: The authors thank Sameer Desai of the Centre for Health Evaluation and Outcome Sciences (CHÉOS) for statistical support during the protocol development and data analysis phases of part 1 of this study.

\section{BEST..is better}

\section{One resource for all types of compounding by pharmacies}

\section{WHAT'S INSIDE?}

- Information for pharmacists, pharmacy technicians, planners, architects, engineers-and others who are involved in decisions or activities that affect compounding

- Guidelines for aseptic compounding, non-aseptic compounding, and compounding which involves hazardous drugs-including radiopharmaceuticals

- Best and leading guidelines on topics such as training, planning and designing the physical environment, developing an air quality strategy, cleaning and decontaminating areas, monitoring the environment, garbing and hand hygiene, developing compounding procedures, documenting, and much more-all in only 230 pages

\section{(} (

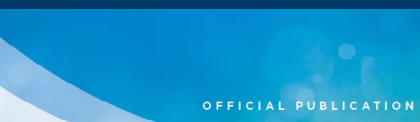

Compounding: Guidelines for Pharmacies

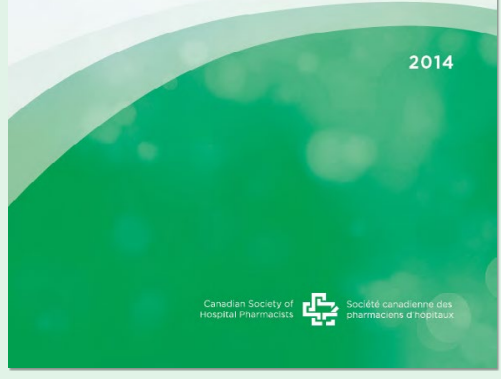

Learn what best looks like: add this publication to your library!
HAVE A SNEAK PEEK OR ORDER AT: https://www.cshp.ca/site/res/other/guidelines?nav=resources CSHP MEMBERS PAY A DISCOUNTED PRICE
Canadian Society of Hospital Pharmacists
Société canadienne des pharmaciens d'hôpitaux 